\title{
Performance Investigation of Tunnel Lining with Cavities around Surrounding Rocks
}

\author{
Jiajia Li, ${ }^{1,2}$ Yong Fang $\mathbb{D}^{2}{ }^{2}$ Cheng Liu,, ${ }^{1}$ Yongxing Zhang $\mathbb{D}^{1,2}$ and Weihua Lu $\mathbb{D}^{1}$ \\ ${ }^{1}$ Nanjing Forestry University, Hunan Provincial Key Laboratory of Hydropower Development Key Technology, Nanjing, China \\ ${ }^{2}$ Key Laboratory of Transportation Tunnel Engineering (Southwest Jiaotong University), Ministry of Education, Chengdu, China
}

Correspondence should be addressed to Yongxing Zhang; zhanguongxing81@aliyun.com

Received 4 June 2019; Accepted 12 December 2019; Published 11 January 2020

Academic Editor: Xuemei Liu

Copyright (C) 2020 Jiajia Li et al. This is an open access article distributed under the Creative Commons Attribution License, which permits unrestricted use, distribution, and reproduction in any medium, provided the original work is properly cited.

This paper presents a systematical numerical investigation into the lining performance of a tunnel with cavities around surrounding rocks, focusing on the influences of cavity size and multicavity distribution. The study demonstrates that the cavities around surrounding rocks have much influence on tunnel stability and may induce damages in tunnel structures, in which cavity width has a more severe effect on the stress state of tunnel structures than cavity depth. Moreover, the numerical investigation also illustrates that the nonadjacent distribution of multicavities has more serious influence on tunnel structures than that from adjacent distribution of multicavities as well as that from a single cavity.

\section{Introduction}

Tunnels have been increasingly used in transportation infrastructure, since they have obvious advantages of saving surface space as well as traversing mountains and rivers $[1,2]$. Damage often appears in tunnel structures, which may affect the stability of the tunnel $[3,4]$. However, the cause of tunnel damage is not easily identified due to various complex influencing factors $[5,6]$. In view of previous studies, tunnel structures are mainly suffered from harsh geological or topographical environments around the tunnel site [7-9], insufficient bearing capacity [10], unexpected external load $[11,12]$, and degraded material properties $[13,14]$. Especially, the studies performed by authors have demonstrated that the construction deficiency of cavities around surrounding rocks can also induce landslides during tunneling as well as damages in tunnel lining $[15,16]$, which are resulted from tunneling without timely backfilling. Therefore, further study related to tunnel-damaging behavior is required, which is expected to support the guidance for reasonably strengthening the damaged tunnel structures.

In this paper, the performance of a tunnel lining with cavities around surrounding rocks is systematically investigated by numerical analysis. The study focuses on the influence of varied cavity sizes as well as multicavity distribution.

\section{Program for Numerical Investigation}

2.1. Numerical Schemes. Figure 1 demonstrates the numerical model and mesh size, selected from the typical transverse section of a railway tunnel with $10.5 \mathrm{~m}$ height and $8.9 \mathrm{~m}$ width [15], in which cavities around surrounding rocks are considered. The numerical analysis is performed using Abaqus software [17]. Moreover, the following calculation range and boundary conditions are adopted in the numerical model, since the accuracy of numerical results can be ensured with the calculation range larger than five times the size of the tunnel. The longitudinal calculation range is $120 \mathrm{~m}$, the vertical calculation ranges of both lateral sides are $80 \mathrm{~m}$ including $30 \mathrm{~m}$ buried depth, and a fine mesh is adopted around the tunnel within the $30 \mathrm{~m} \times 30 \mathrm{~m}$ area as shown in Figure 1(b). Some assumptions are adopted for boundary conditions, in which the displacements of the lower boundary are constrained in longitudinal and vertical directions, and those of both lateral boundaries are restricted in the longitudinal direction, but those of the upper 


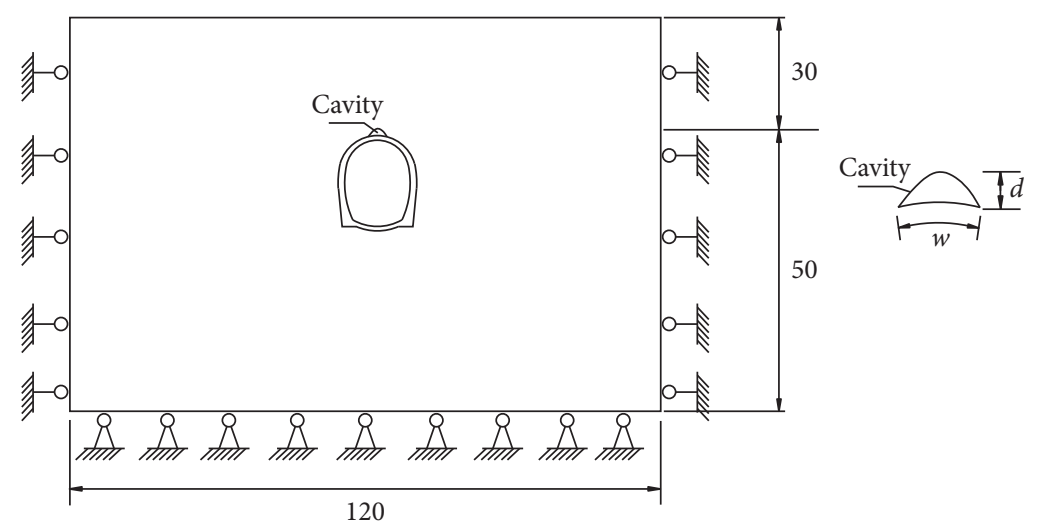

(a)

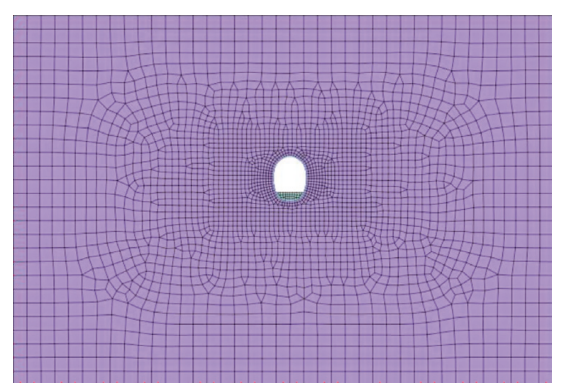

(b)

Figure 1: Schemes for numerical simulation (unit: m). (a) Numerical model. (b) Mesh size.

TABLE 1: Cases in groups 1 and 2.

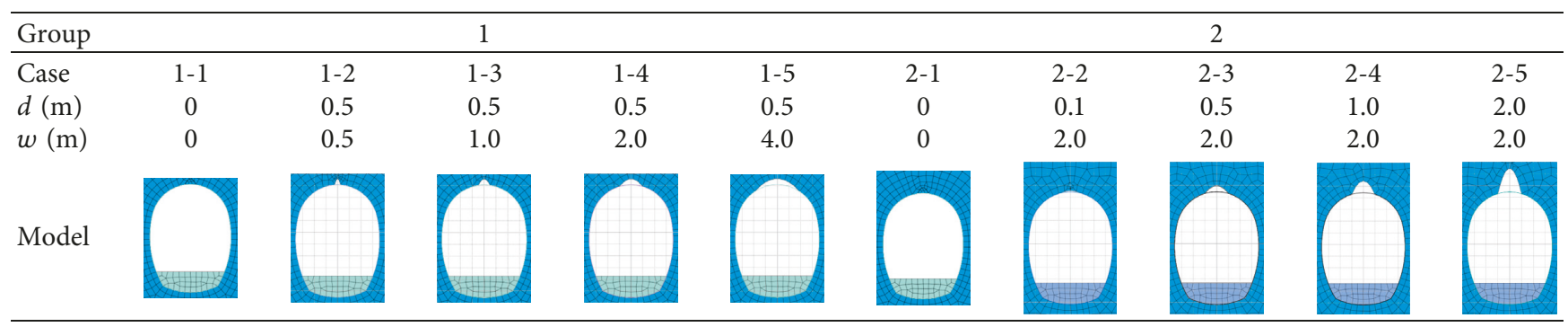

boundary are free in both longitudinal and vertical directions.

The different cases with cavities around surrounding rocks are divided into three groups, in which groups 1 and 2, respectively, focus on the influence of varied cavity width and depth and group 3 takes account of the influence of multicavity distribution.

In groups 1 and 2 as listed in Table 1, a single cavity is prepared around the arch vault of the tunnel lining in all the cases, in which cavity widths of all the cases in group 1 are gradually increased with the same $0.5 \mathrm{~m}$ depth, and cavity depths of all the cases in group 2 are gradually increased with the same $2.0 \mathrm{~m}$ width.

In group 3 as shown in Figure 2, a single cavity is prepared behind the arch vault of the tunnel lining in case 31, two cavities are, respectively, prepared behind the arch vault and the spandrel of the tunnel lining in case 3-2, and two cavities are symmetrically distributed behind both spandrels of the tunnel lining in case 3-3, in which all the cavities have $2.0 \mathrm{~m}$ width and $0.5 \mathrm{~m}$ depth.

Besides, the sectional sizes of the concrete lining are shown in Figure 3, in which the arch vault and arch foot have $50 \mathrm{~cm}$ and $72 \mathrm{~cm}$ thicknesses, respectively, and that of the side wall is $111 \mathrm{~cm}$.

2.2. Material Property. The surrounding rocks are considered as ideal elastic-plastic materials meeting the Mohr-Coulomb yield criterion [15], and the elastic-plastic constitutive model is adopted for lining concrete. The

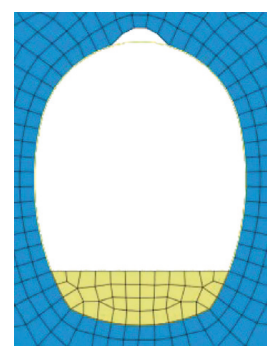

(a)

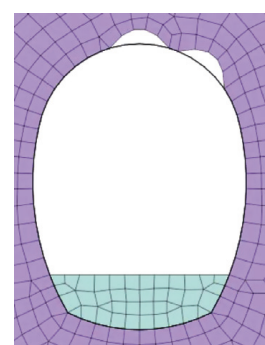

(b)

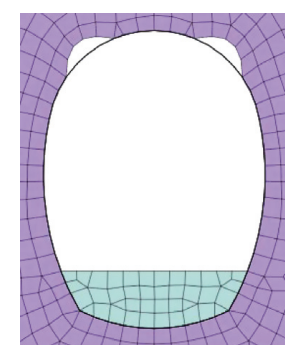

(c)
Figure 2: Cases in group 3. (a) Case 3-1. (b) Case 3-2. (c) Case 3-3.

surrounding rocks and concrete lining are, respectively, simulated using solid and beam elements, and their physical properties are listed in Table 2.

\section{Results from Numerical Investigation}

3.1. Internal Forces of Tunnel Lining Influenced by Varied Cavity Sizes. Figures 4 and 5 demonstrate the distribution of numerical axial forces and bending moments along the concrete lining in groups 1 and 2 . It can be clearly seen that the concrete linings are subject to compressive axial forces, whereas the bending moments are continuously varied with negative and positive values along the concrete lining. The lining sections with maximum moments are adjacent to the cavity in all the cases with cavity, which are different from those of the arch vault in cases 1-1 and 2-1 without cavity. Moreover, both axial forces and bending moments of all the 


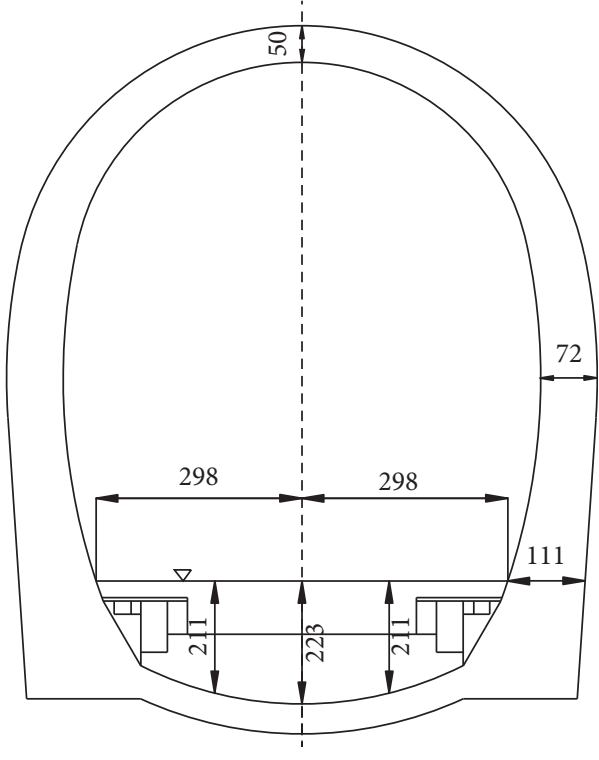

FIgURE 3: Transverse section of the tunnel lining (unit: $\mathrm{cm}$ ).

TABLE 2: Material properties of concrete lining and surrounding rocks.

\begin{tabular}{lc}
\hline Material & Physical and mechanical parameters \\
\hline Surrounding rock & $E=500 \mathrm{MPa}, \rho=2200 \mathrm{~kg} / \mathrm{m}^{3}, \mu=0.35$, \\
$c=200 \mathrm{kPa}, \varphi=30^{\circ}$, \\
Concrete lining & $E=28 \mathrm{GPa}, \rho=2400 \mathrm{~kg} / \mathrm{m}^{3}, f_{c}=11 \mathrm{MPa}$, \\
$f_{t}=1.1 \mathrm{MPa}, \mu=0.2$
\end{tabular}

cases are similar in group 2, whereas those in case 1-5 are significantly varied from those of other cases in group 1 . This behavior illustrates that cavities around surrounding rocks have much influence on tunnel stability, in which cavity width has a more severe effect on the stress state of the tunnel structure than cavity depth.

Table 3 shows the calculated lining section stress of the cases in groups 1 and 2, in which compressive stress is ruled as positive. It is obviously seen that the stresses of most lining sections are subject to compressive stresses, which are smaller than the compressive strength of lining concrete as listed in Table 2. However, the stresses of several lining sections around cavity are subject to tensile stresses at outer surfaces, larger than the tensile strength of lining concrete as listed in Table 2. This behavior also illustrates the tunnel structure can be damaged with the increasing cavity size, in which the cavity width has a more severe effect on the stress state of tunnel structures than that influenced by cavity depth.

3.2. Internal Forces of Tunnel Lining Influenced by Multicavity Distribution. Figure 6 shows the distribution of numerical axial forces and bending moments along the concrete lining in group 3. It is obviously seen that the concrete linings of the cases are also subject to compressive axial forces with similar distribution, whereas the bending moments are different from one another with continuously varied negative and positive values along the concrete lining in all the

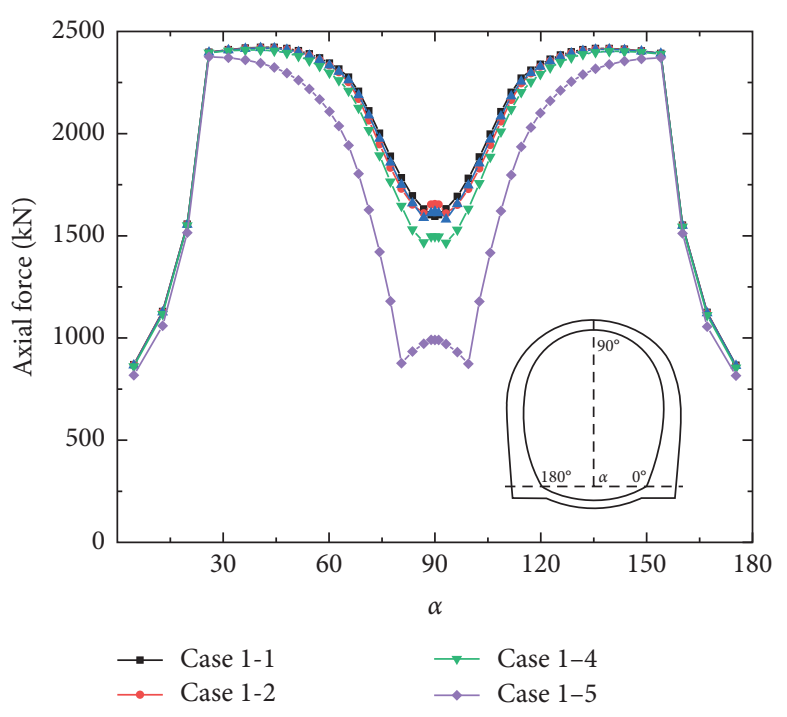

(a)

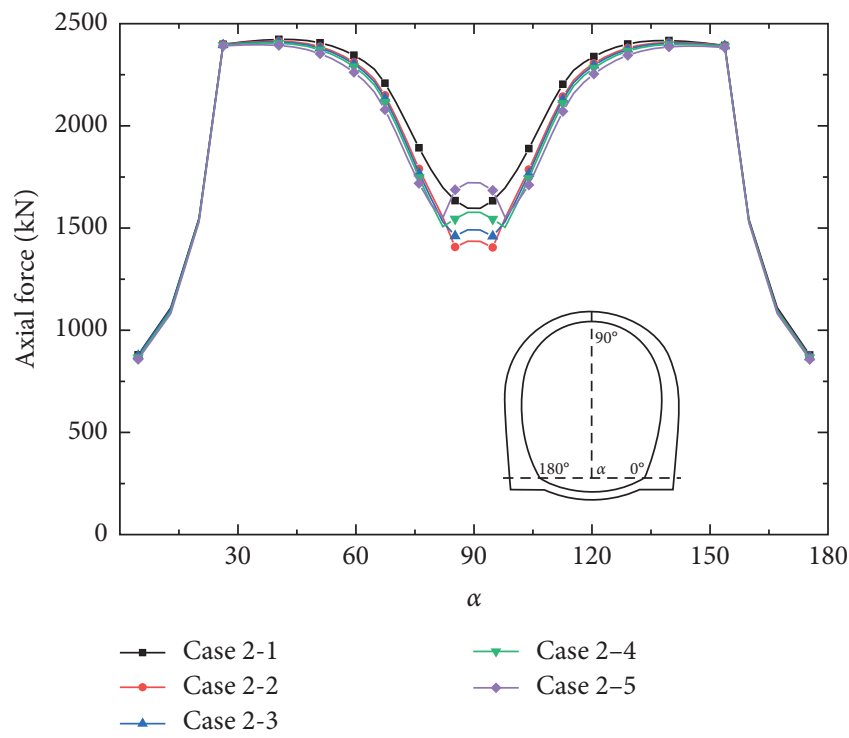

(b)

Figure 4: Axial forces of concrete lining. (a) Group 1. (b) Group 2.

cases. Moreover, the maximum moment of the lining section in case 3-3 is much larger than those in other cases, and the lining section with maximum moment in case $3-3$ is also varied from those in other cases.

Table 4 shows the calculated lining section stress of the cases in group 3, in which compressive stress is ruled as positive. Similar with those in groups 1 and 2 , most lining sections are subject to compressive stresses and smaller than the compressive strength of lining concrete. However, several surface stresses of lining sections around cavities are subject to tensile stresses, in which those in case 3-3 with nonadjacent distribution of multicavities are greater than those in case 3-2 with adjacent distribution of multicavities. Especially, the lining section stress of cases 3-2 and 3-3 with multicavities is significantly larger than that in case 3-1 with single cavity as well as the tensile strength of lining concrete 


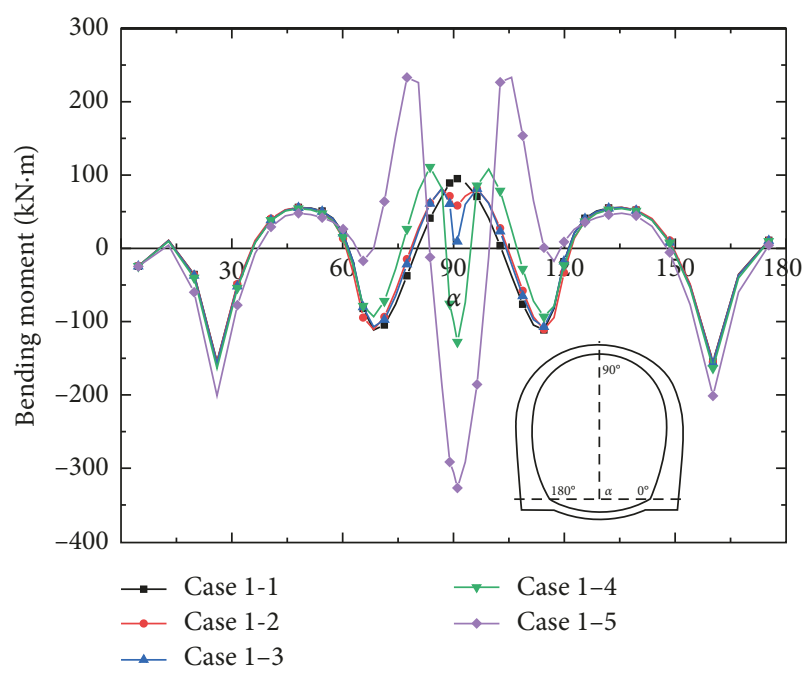

(a)

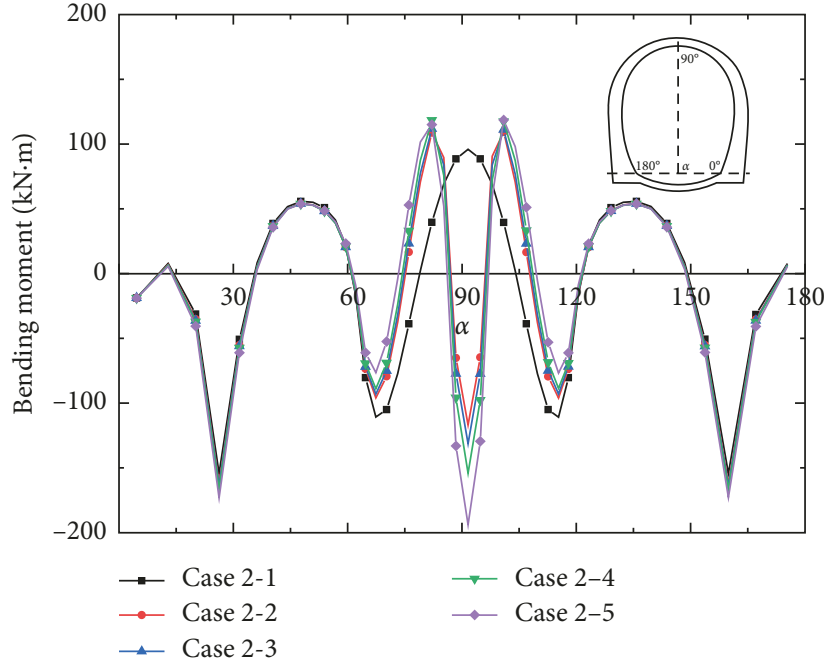

(b)

Figure 5: Bending moments of concrete lining. (a) Group 1. (b) Group 2.

TABLE 3: Calculated stresses of selected lining sections in groups 1 and 2.

\begin{tabular}{|c|c|c|c|c|c|c|c|c|c|c|}
\hline \multirow{2}{*}{ Surface } & \multirow{2}{*}{ Case } & \multicolumn{4}{|c|}{ Lining section } & \multirow{2}{*}{ Case } & \multicolumn{4}{|c|}{ Lining section } \\
\hline & & $25^{\circ}$ & $50^{\circ}$ & $75^{\circ}$ & $90^{\circ}$ & & $25^{\circ}$ & $50^{\circ}$ & $75^{\circ}$ & $90^{\circ}$ \\
\hline \multirow{5}{*}{ Outer surface } & $1-1$ & 1.55 & 3.54 & 2.88 & 5.48 & $2-1$ & 1.55 & 3.54 & 2.88 & 5.48 \\
\hline & $1-2$ & 1.54 & 3.54 & 3.31 & 4.70 & $2-2$ & 1.48 & 3.51 & 3.61 & 0.06 \\
\hline & $1-3$ & 1.53 & 3.53 & 3.20 & 3.45 & $2-3$ & 1.46 & 3.50 & 4.16 & -0.08 \\
\hline & $1-4$ & 1.46 & 3.50 & 4.16 & -0.08 & $2-4$ & 1.43 & 3.49 & 3.85 & -0.54 \\
\hline & $1-5$ & 1.08 & 3.32 & 7.95 & -5.86 & $2-5$ & 1.37 & 3.47 & 4.02 & -1.21 \\
\hline \multirow{5}{*}{ Inner surface } & $1-1$ & 4.44 & 2.50 & 4.68 & 0.93 & $2-1$ & 4.44 & 2.50 & 4.68 & 0.93 \\
\hline & $1-2$ & 4.45 & 2.49 & 4.02 & 1.91 & $2-2$ & 4.52 & 2.50 & 3.45 & 5.68 \\
\hline & $1-3$ & 4.47 & 2.49 & 4.24 & 3.00 & $2-3$ & 4.53 & 2.49 & 2.90 & 6.06 \\
\hline & $1-4$ & 4.53 & 2.49 & 2.90 & 6.06 & $2-4$ & 4.55 & 2.48 & 3.20 & 6.85 \\
\hline & $1-5$ & 4.86 & 2.42 & -3.23 & 9.83 & $2-5$ & 4.61 & 2.46 & 6.23 & 8.10 \\
\hline
\end{tabular}

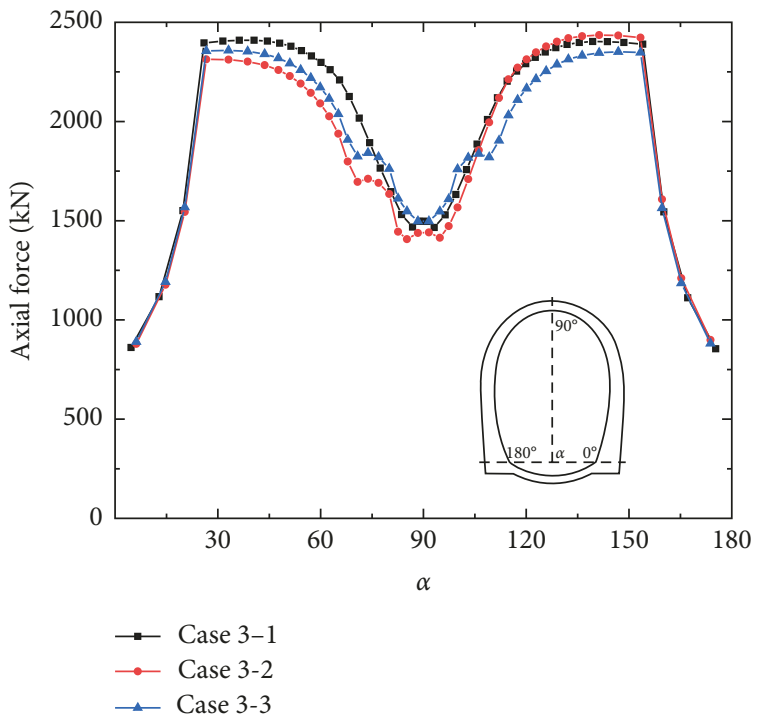

(a)

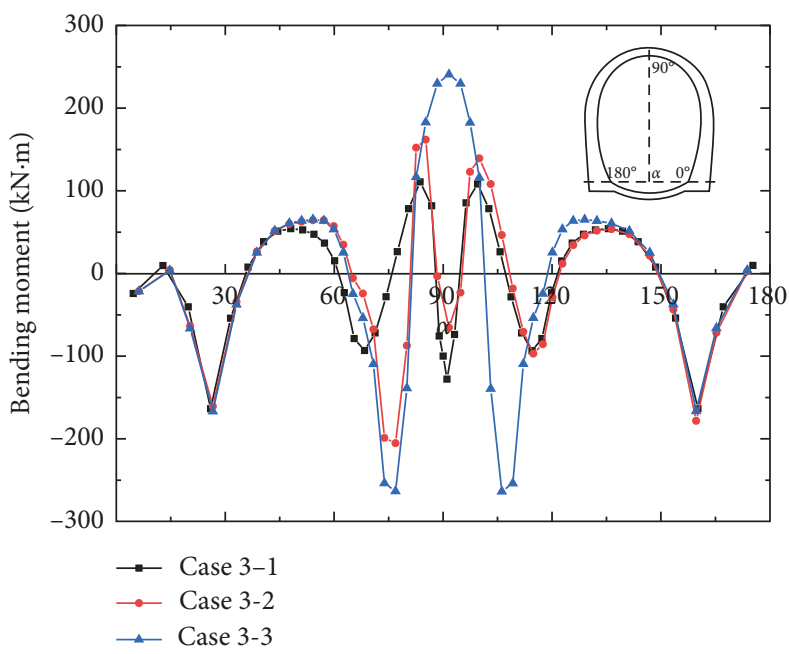

(b)

FiguRe 6: Internal forces of concrete lining in group 3. (a) Axial forces. (b) Bending moments. 
TABLE 4: Calculated stresses of selected lining sections in group 3.

\begin{tabular}{lcccccccc}
\hline \multirow{2}{*}{ Surface } & \multicolumn{1}{c}{ Lining section } \\
& Case & \multicolumn{8}{c}{$55^{\circ}$} & $50^{\circ}$ & $75^{\circ}$ & $90^{\circ}$ & $100^{\circ}$ & $135^{\circ}$ & $160^{\circ}$ \\
\hline \multirow{3}{*}{ Outer surface } & $3-1$ & 1.46 & 3.50 & 4.16 & -0.08 & - & - & - \\
& $3-2$ & 1.38 & 3.38 & -1.35 & 1.31 & 6.47 & 3.54 & 0.34 \\
& $3-3$ & 1.38 & 3.47 & -2.40 & 8.78 & -2.30 & 4.99 & 0.40 \\
\hline \multirow{4}{*}{ Inner surface } & $3-1$ & 4.53 & 2.49 & 2.90 & 6.06 & - & - & - \\
& $3-2$ & 4.40 & 2.26 & 8.19 & 4.45 & -0.21 & 2.54 & 3.68 \\
& $3-3$ & 4.51 & 2.27 & 9.77 & -2.78 & 10.30 & 3.11 & 3.52 \\
\hline
\end{tabular}

listed in Table 2. This behavior illustrates that the multicavities around surrounding rocks have more serious influence on the stress state of the tunnel structure than that influenced by a single cavity around surrounding rocks. Moreover, nonadjacent distribution of multicavities has greater effect on tunnel stability than adjacent distribution of multicavities.

\section{Conclusions}

In this paper, the systematical numerical investigation into damages in tunnel structures induced by cavities around surrounding rocks is carried out, and the following conclusions can be drawn:

(1) Cavities around surrounding rocks have much influence on tunnel stability, in which tunnel structures can be damaged with the increasing cavity size. Especially, cavity width has a more severe effect on the stress state of tunnel structures than cavity depth.

(2) The multicavities around surrounding rocks have a more severe effect on the stress state of tunnel structures than a single cavity around surrounding rocks. Moreover, nonadjacent distribution of multicavities has greater influence on tunnel stability than adjacent distribution of multicavities.

\section{Data Availability}

The data used to support the findings of this study are included within the article.

\section{Conflicts of Interest}

The authors declare that they have no conflicts of interest.

\section{Acknowledgments}

The author would like to acknowledge the support from the National Natural Science Foundation of China (No. 51578292, 51508278, 51508279), Postgraduate Research and Practice Innovation Program of Jiangsu Province (KYCX18_0972), Open Research Fund of Hunan Provincial Key Laboratory of Hydropower Development Key Technology (PKLHD201803), Open Fund of Key Laboratory of Transportation Tunnel Engineering of Ministry of Education (Southwest Jiaotong University, TTE2017-02), Six Talent Peak Projects, and Qinglan Project.

\section{References}

[1] C. He, P. Geng, Q. X. Yan, and K. Feng, "Status of seismic analysis methods for traffic tunnel and their applicability in China," Journal of Earthquake and Tsunami, vol. 7, no. 3, pp. 1-23, 2013.

[2] J. S. Yang, D. M. Gou, and Y. X. Zhang, "Field measurements and numerical analyses of double-layer pipe roof reinforcement in a shallow multiarch tunnel," Transportation Research Record: Journal of the Transportation Research Board, vol. 2050, no. 1, pp. 145-153, 2008.

[3] Y.-C. Chiu, T.-T. Wang, and T.-H. Huang, "Investigating continual damage of a nineteenth century masonry tunnel," Proceedings of the Institution of Civil Engineers-Forensic Engineering, vol. 167, no. 3, pp. 109-118, 2014.

[4] R. Lackner and H. A. Mang, "Cracking in shotcrete tunnel shells," Engineering Fracture Mechanics, vol. 70, no. 2-3, pp. 1047-1068, 2003.

[5] A. Lipponen, S. Manninen, H. Niini, and E. Rönkä, "Effect of water and geological factors on the long-term stability of fracture zones in the Päijänne tunnel, Finland: a case study," International Journal of Rock Mechanics and Mining Sciences, vol. 42, no. 1, pp. 3-12, 2005.

[6] J. S. Lee, H. Y. Choi, H. U. Lee, and H. H. Lee, "Damage identification of a tunnel liner based on deformation data," Tunnelling and Underground Space Technology, vol. 20, no. 23, pp. 73-80, 2005.

[7] S. Wang, P. Yang, and Z. Yang, "Characterization of freezethaw effects within clay by 3D X-ray computed tomography," Cold Regions Science and Technology, vol. 148, pp. 13-21, 2018.

[8] M. B. Prendes-Gero, F. Lopez-Gayarre, C. Menendez-Fernandez, and M. Rodriguez-Avial Llardent, "Forensic analysis of the failure of the foundations of a tunnel built to channel the course of a river," Engineering Failure Analysis, vol. 32, pp. 152-166, 2013.

[9] X. Zhang, J. Yang, Y. Zhang, and Y. Gao, "Cause investigation of damages in existing building adjacent to foundation pit in construction," Engineering Failure Analysis, vol. 83, pp. 117124, 2018.

[10] S. Wang, Y. Jian, X. Lu, L. Ruan, W. Dong, and K. Feng, "Study on load distribution characteristics of secondary lining of shield under different construction time," Tunnelling and Underground Space Technology, vol. 89, no. 7, pp. 25-37, 2019.

[11] J. Deng and M. Xiao, "Dynamic response analysis of concrete lining structure in high pressure diversion tunnel under seismic load," Journal of Vibroengineering, vol. 18, no. 2, pp. 1016-1030, 2016.

[12] B. X. Han and L. X. Li, "The analysis of the concrete lining damage under blast load," Applied Mechanics and Materials, vol. 638-640, no. 638-640, pp. 846-850, 2014.

[13] Y. Wei, X. Zhang, G. Wu, and Y. Zhou, "Behaviour of concrete confined by both steel spirals and fiber-reinforced polymer under axial load," Composite Structures, vol. 192, no. 5, pp. 577-591, 2018.

[14] Y. X. Zhang, Y. Fang, W. H. Lu et al., "Shrinkage behavior influence of strain hardening cementitious composites," Structural Concrete, vol. 20, no. 6, pp. 1-9, 2019.

[15] Y. X. Zhang, Y. F. Shi, Y. D. Zhao, and J. S. Yang, "Damage in concrete lining of an operational tunnel," Journal of Performance of Constructed Facilities, vol. 31, no. 4, 2017.

[16] Y. Zhao, C. Liu, Y. Zhang, J. Yang, and T. Feng, "Damaging behavior investigation of an operational tunnel structure induced by cavities around surrounding rocks," Engineering Failure Analysis, vol. 99, pp. 203-209, 2019.

[17] Dassault Simulia International Inc., 2004, http://www.abaqus. com. 


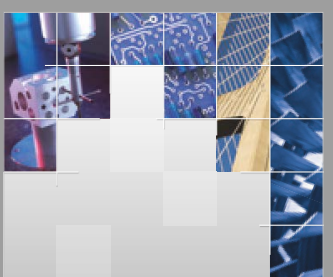

\section{Enfincering}
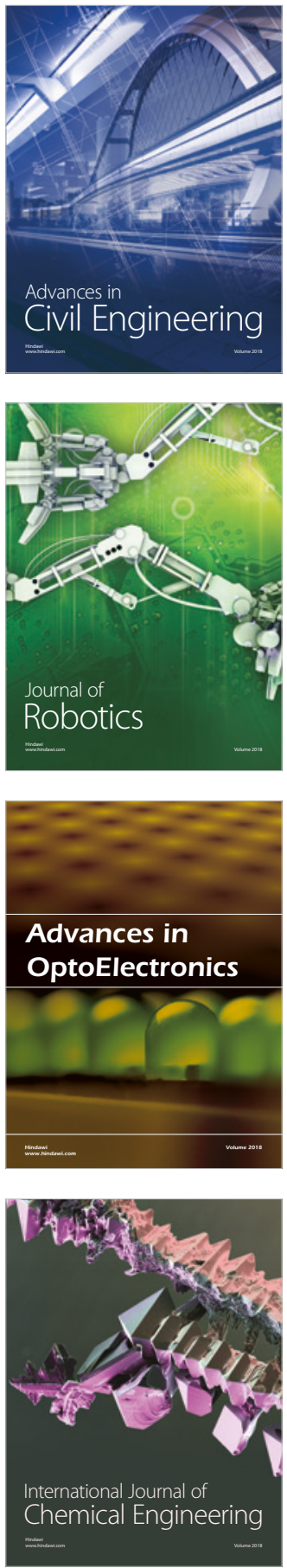

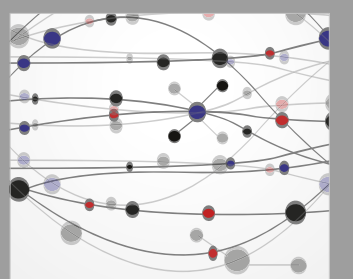

\section{Rotating \\ Machinery}

The Scientific World Journal

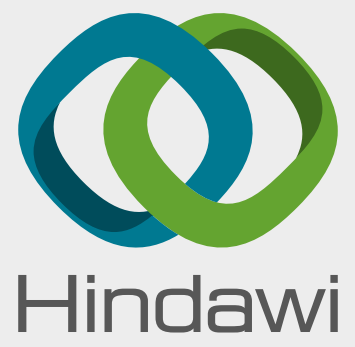

Submit your manuscripts at

www.hindawi.com
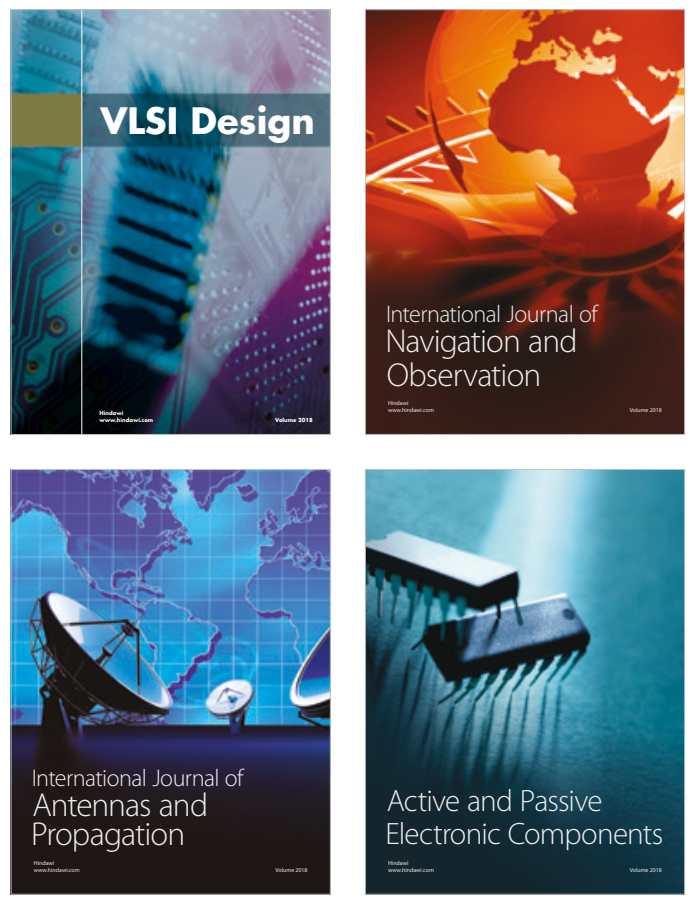
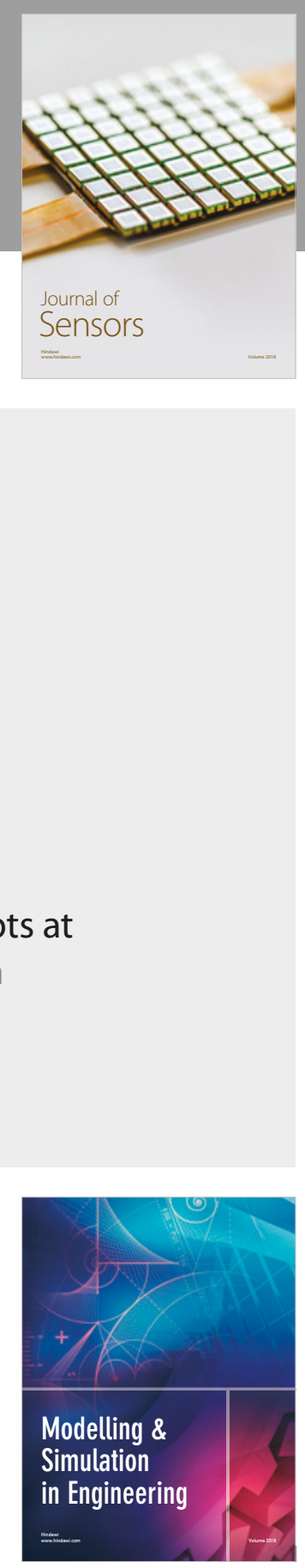

\section{Advances \\ Multimedia}
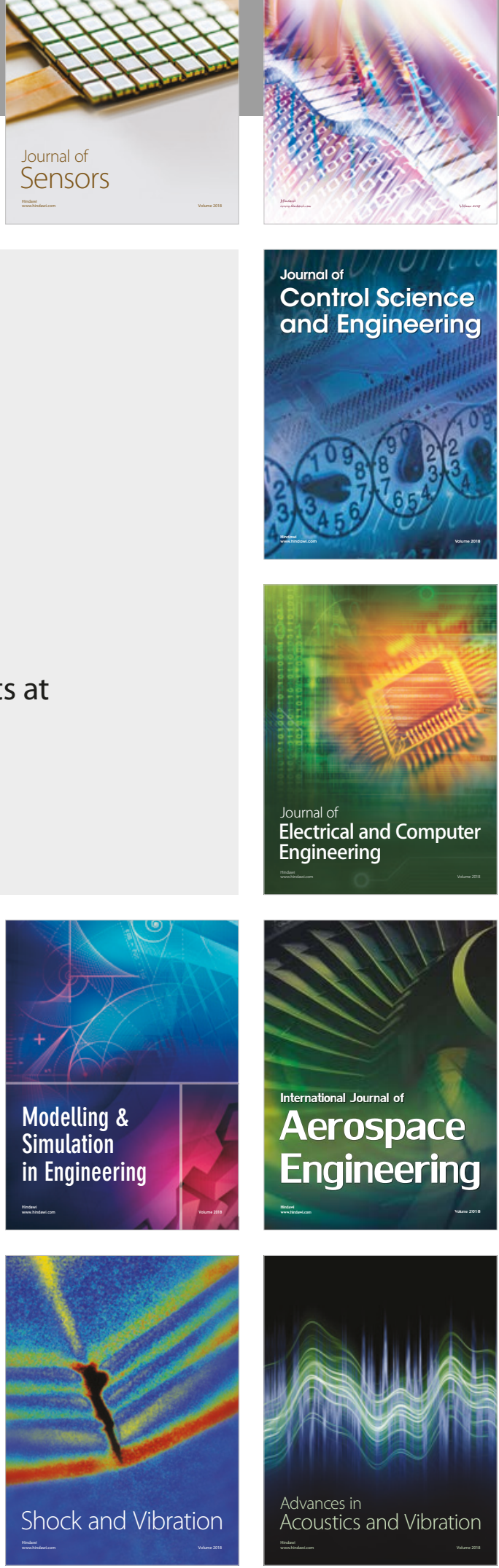